\title{
A sentença no novo processo de nulidade matrimonial ${ }^{1}$
}

\author{
The sentence in the new matrimonial nullity process
}

\section{Manuel Jesús Arroba Conde ${ }^{2}$}

\begin{abstract}
Resumo: A imutabilidade da disciplina sd Abstract: The immutability of the disc sentença no novo processo; a decisão e a about the sentence in the new process; the epistêmica do processo: o peso do col sion and the epistemic view of the proces hermenêutico; alguns aspectos do contes value of the hermeneutic context; some as clesial e normativo úteis à decisão; o priı of the ecclesial and normative context 1 de legalidade e o empenho para decidir ses for the decision; the principle of legalit. a equidade; a certeza moral para decidir $\mathrm{e}$; the commitment to decide according to $\mathrm{e}$
\end{abstract}

1 Quinta conferência proferida no II ${ }^{\circ}$ Simpósio Canônico "Questões seletas de Direito Matrimonial e Penal Canônico", promovido pelo Instituto Superior de Direito Canônico Santa Catarina em 8-9 de maio de 2018.

2 Doutor, Professor e Presidente do Institutum Utriusque Iuris da Pontificia Universidade Lateranense de Roma. Recentes publicações do autor sobre o tema da conferência: com C. Izzi, Pastorale giudiziaria e prassi processuale nelle cause di nullità del matrimonio, Cinisello Balsamo 2017; com M. Riondino, Introduzione al diritto canonico, Milano 2015; Convincimento, certezza e motivazione: l'esperienza canonica, en Criminalia (2012), 163-180; Corresponsabilità e diritto processuale, in Apollinaris 82 (2009), 201-225; Cuestiones fundamentales de derecho probatorio canónico, en R. Rodríguez Chacón (ed.), Puntos de especial dificultad en derecho matrimonial canónico, sustantivo y procesal, y cuestiones actuales de derecho eclesiástico y relaciones Iglesia - Estado (XXVII Jornada de la asociación de canonistas españoles (11 al 13 abril), Madrid 2007, $105-$ 129; Diritto processuale canonico, $6^{\circ}$ ed., Roma 2012; Giusto processo e peculiarità culturali del processo canonico, Roma 2016; La pastoral judicial y la preparación de la causa en el m.p. Mitis Iudex Dominus Iesus, in M. E. Olmos Ortega (ed.), Procesos de nulidad matrimonial tras la reforma del papa Francisco, Madrid, 2016, 63-82; La reciente experiencia sinodal y la reforma procesal, en Anuario de derecho canónico 5 (2016), 165-192; Relaciòn entre las pruebas y la comprobaciòn de la verdad en el proceso canònico, en Anuario de derecho canonico 1 (2012), 11-36; Risultati della prova e tecnica motivazionale nelle cause di nullità matrimoniale. Casi pratici di prima istanza, Città del Vaticano 2013. 
tribuição das partes; a idoneidade da moti e a aceitação da decisão por parte dos dest rios; as obrigações decorrentes da senter responsabilidade familiar e o desejo de fa a dedicação prioritária: tempo e destinaç decisão.

Palavras-chave: Sentença no novo pro Destinatário da sentença. Hermenêutica ca. Equidade. Certeza moral. moral certainty to decide and the contrit of the parties; the appropriateness of the vation and the acceptance of the decision 1 addressees; the obligations arising fror sentence: family responsibility and famil sire; the priority dedication: time and de tion of the decision.

Keywords: Sentence in the new process. Addressee of the sentence. Juridical hermeneutics. Equity. Moral certainty.

\section{Introdução}

Poderíamos em poucas palavras colocar um fim à reflexão sobre a sentença no novo processo matrimonial, limitando-nos a assinalar a substancial identidade das normas que disciplinam diretamente os seus elementos essenciais. Na realidade, trata-se de normas pertencentes à segunda parte do Livro VII, relativa aos processos contenciosos, não sendo, portanto, objeto de uma específica tratativa na parte correspondente aos processos de nulidade matrimonial. Na referida seção, o legislador, tanto no Código, quanto nos cânones do motu proprio da reforma, se limita a regular aspectos importantes, mas não diretamente referentes ao objeto intrínseco deste ato jurídico, que é o pronunciamento autorizado sobre a causa tratada em juízo. Assim, sobre as condições subjetivas para prolatar a sentença, sobre as dinâmicas previstas para se chegar à decisão, sobre seus conteúdos substanciais e formais e sobre seu efetivo valor por meio de regular publicação, nada se pode dizer a respeito de mudanças na recente reforma, permanecendo em vigor (em força do reenvio conclusivo estabelecido ao cân. 1691) as disposições gerais sobre pronunciamentos definitivos (cân.1607 e ss.) aplicáveis, também, (com adaptações de menor importância) às decisões das causas tratadas segundo o assim chamado processo brevior.

\section{A imutabilidade da disciplina sobre a sentença no novo processo}

Na realidade, não se encontra modificações significativas nem mesmo sobre os aspectos extrínsecos da sentença, regulados na específica seção sobre a causa de nulidade matrimonial. De fato, fora o eventual efeito de exe- 
cução ora reconhecido na sentença que declara a nulidade pela primeira vez se não for apelada nos termos peremptórios estabelecidos, as disposições precedentes e aquelas atuais são idênticas.

Estas premissas que justificam a impostação da reflexão sucessiva seriam incompletas se à advertência sobre a ausência de mudanças nas normas que disciplinam diretamente a sentença, não se acrescentasse, também, uma referência similar sobre a idêntica imutabilidade das normas a respeito da aquisição das provas no desenvolvimento dos processos cuja relação substancial com a sentença é óbvia. A falta de mudanças se refere mais ao papel que cabe ao aparato probatório realizado no processo enquanto premissa para a decisão. Todavia, deveria ser objeto de esclarecimento a incidência que na produção das provas poderia ter a eventual investigação pastoral préprocessual (à qual as normas de procedimento faz referência) como, também, as provas aduzidas junto ao libelo, particularmente na instrução e cognição sumária prevista para o processo chamado de brevior, deixando claro que tal processo se concluirá com um decreto de envio para o exame ordinário, e não com uma sentença, se da verificação dos fatos na instrução não resultar suficiente demonstrada a nulidade.

A referida imutabilidade da disciplina substancial sobre a sentença e a aquisição da prova provém da opção de fundo mais determinante na obra de reforma; uma opção amadurecida progressivamente no contexto sinodal e manifestada pelo legislador em modo claro no Proêmio do motu proprio: a manutenção da via judicial como a única de fato a ser percorrida para a revisão da validade ou nulidade do vínculo conjugal, pois aporta maiores garantias à tutela da verdade efetiva que proporciona o processo judicial. Tal opção implica em reafirmar que também o novo processo deva continuar a ser compreendido como um conjunto estruturado de atividades voltadas para o conhecimento verdadeiro sobre fatos relevantes. E ainda referente ao nosso tema, esta opção comporta que a sentença no novo processo deve continuar a ser entendida como um conjunto coerente de enunciados emergidos, de fato, no processo e que sustentam ou justificam o pronunciamento do juiz.

Esta é também a concepção da atividade judicial proposta pela doutrina extra-canônica mais aceita ou, ao menos a mais convincente e útil para os nossos objetivos, ou seja, aquela que insiste sobre valor epistemológico do processo canônico. Assim, no que se refere a sentença, entendida seja como pronunciamento, seja como ato formal em cujo pronunciamento se exprime, 
as peculiaridades canônicas não só não diminuem, mas chamam a atenção de modo ainda mais forte quando se considera o peso que o ordenamento canônico atribui ao favor veritatis nos processos sobre o estado das pessoas. Tal horizonte deveria, de fato, acentuar a ideia (tida como irrenunciável na citada visão do processo) de que nem a atividade processual, nem o ato decisório com o qual se conclui o processo, podem ser concebidos como um mero exercício de um poder de império, mas, sim, e de modo prevalente, como atividade vinculante para conhecimento dos fatos necessários para se decidir.

\section{A decisão e a visão epistêmica do processo: o valor do contexto her- menêutico}

Se não foram alteradas as normas sobre sentença e nem as normas relativas a produção da prova (que é o instrumento processual previsto para o conhecimento dos fatos), a quais outras mudanças inerentes à reforma do processo e que seriam potencialmente relevantes para tratar o nosso tema poderíamos, então, nos referir? Tenha-se presente que nem mesmo nas Regras de Procedimento que sucedem aos novos cânones encontra-se alguma norma relativa à sentença da qual se possa afirmar que é verdadeiramente nova. Pelo contrário, sobre este setor (constituído de dois artigos), o legislador se serviu somente de normas da Dignitas Connubii, tornando assim quase que ridícula qualquer afirmação difamatória sobre a utilidade daquela instrução.

Não obstante tudo isso, consideraria equivocado refletir sobre a sentença, enfatizando em excesso a permanência das normas; vale a pena esforçar-se para considerar outros aspectos, nem todos expressos diretamente no texto normativo, sobre cuja configuração seria insensato negar que tenha havido uma notável renovação. Trata-se dos aspectos que os processualistas da corrente de pensamento antes citada costumam exprimir recorrendo ao conceito de "contexto hermenêutico", entendendo com isso o conjunto de fatores frequentemente só latentes, mas que influem no processo de decisão. Com efeito, seria redutivo considerar a decisão como mero silogismo, tendo por objeto a exclusiva aplicação de uma cadeia de regras lógico-formais. Os autores advertem que a tais regras, embora necessárias, se acrescenta o senso comum e o contexto cultural que anima o processo; mais precisamente, 
trata-se de cultura entendida não só como técnica normativa, mas também como ideologia, isto é, como conjunto de valores compartilhados daquela comunidade prática que constituem os direitos dos participantes ao processo e a mais ampla comunidade social de referência.

Afirmar a incidência desses aspectos não significa diminuir a função que cabe ao processo no sentido de determinar, por meio de regras objetivas, a verdade dos fatos. Não seria jamais concebida como integralmente justa uma decisão fundada sobre erros relativos a existência deles ou sobre fatos falsos, o que já não ocorreria se fosse fundada sobre uma errada aplicação do direito substancial. Pode-se dizer que os fatores do contexto hermenêutico, cultural e expressivos do sentir renovado da comunidade, dão um rosto concreto às imprescindíveis análises das provas e, particularmente, aos critérios de comprehensiveness e completeness necessários, mas, também, suficientes, para alcançar a certeza moral, bem como as correspondentes garantias de credibilidade a serem expressas nas motivações e justificativas da decisão. Esta espécie de combinação entre instrumentos técnicos do processo e a incidência nele dos valores que se renovam na comunidade, sugerem algumas indicações acerca da sentença voltadas para a sua melhor aceitação por parte dos destinatários diretos e da comunidade eclesial.

\section{Alguns aspectos do contexto eclesial e normativo úteis à decisão}

A respeito do contexto hermenêutico da reforma do processo para as causas de nulidade do matrimônio, é possível indicar pelo menos cinco aspectos, objetos de uma renovada atenção e potencialmente incidentes na sentença. Entre estes merece ser indicado por primeiro aquele relativo à exigência do discernimento de consciência dos fiéis. Trata-se de um aspecto indicado no Proêmio do Legislador como horizonte mais amplo que justifica o critério de acessibilidade e de simplificação que guiaram a reforma do processo cuja realização é, por isso, conexa com o objetivo de favorecer uma maior e mais personalizada integração na comunidade daqueles que experimentaram a falência do próprio matrimônio.

Um segundo aspecto é a conexão entre os citados objetivos de discernimento e integração e atenção prioritária dada, de modo renovado, pelos recentes sínodos à experiência de vida em família na obra de evangelização. 
Prioridade que deve se fazer presente de modo igualmente renovado na sentença conclusiva do novo processo.

A referência aos sínodos nos introduz em um terceiro aspecto do atual contexto hermenêutico, constituído pelo valor da sinodalidade em si mesma como modo de ser Igreja e de nela agir, inclusive no âmbito da administração da justiça. Não parece estranho ao valor da sinodalidade o renovado lugar normativo, colocado nos primeiros artigos das regras de procedimento, onde se une a pastoral judiciária à pastoral ordinária paroquial e diocesana, desenhando de maneira renovada os conteúdos essenciais e os âmbitos referentes a preparação da causa, prevendo, inclusive, uma eventual investigação pré-processual.

O valor da sinodalidade não se esgota no envolvimento de vários agentes de pastoral na fase pré-processual, com funções de aconselhamento, informação e mediação, mas deve atingir, também, e de modo mais claro, o desenvolvimento do próprio processo, reforçando a corresponsabilidade dos operadores na diversidade de papéis que são necessários para uma mais adequada realização da atividade processual, enquanto atividade especializada, necessitada da contribuição de mais operadores tecnicamente preparados (como observado nas assembleias sinodais), seja para a defesa das partes, seja para a defesa eficaz do vínculo. Sei que é arriscado sustentá-lo, mas entendo que esta valorização da defesa técnica e da defesa do vínculo, que ouso indicar como quarto aspecto do contexto hermenêutico, seja, por outro lado, um dado inegável no conjunto da reforma do processo, retamente entendida.

A variedade e a diversidade de papéis que dão um rosto concreto à sinodalidade no agir, são requisitos imprescindíveis para poder cumprir o objetivo institucional de realizar a obra de Justiça e de Verdade. A esses valores, confiados em maneira especial aos Pastores das Igrejas particulares, se refere o legislador nas primeiríssimas palavras do Proêmio dos motu propri$o$, assim como os objetivos de celeridade e acessibilidade não podem ser entendidos em contraste com o princípio de legalidade no julgar e nem com a exigência de verificação no decidir, requerendo, pelo contrário, uma dedicação prioritária dos operadores do direito e que próprio aos Pastores cabe assegurar.

Penso que estes cinco aspectos inerentes ao atual e renovado contexto hermenêutico ao qual é razoável referir a reforma do processo matrimoni- 
al, mesmo sem ter induzido a modificações normativas em sentido estrito, podem enriquecer a interpretação da disciplina sobre a sentença e, concretamente, sobre a relação entre legalidade e equidade na decisão, sobre o conceito de certeza moral, sobre o modo de referir as motivações, sobre a atenção às obrigações decorrentes da decisão e, por último, sobre o tempo e a destinação deste ato.

\section{O princípio de legalidade e o empenho para decidir segundo a equidade}

Com referência ao primeiro elemento, a crescente valorização da natureza pastoral dos processos de nulidade enquanto compreendidos também como um auxílio específico e especializado ao discernimento dos fiéis em situações de fragilidade familiar (devida ao falimento conjugal), enriquece o papel da decisão e aporta uma visão integral (que exige empenho) do princípio de legalidade o qual requer que se resolva segundo a equidade, ainda que em conformidade com o quanto exige a justiça e a verdade.

Decidir segundo equidade é objeto de expressa disposição canônica (cann. 19 e 1752), não sendo adequado estabelecer contraposições abstratas entre as exigências da equidade e o obrigatório princípio de legalidade que caracteriza a ação do poder judicial no sistema canônico. É, porém, necessário adquirir, no atual contexto social e eclesial, uma consciência mais diligente a respeito da conexão e contemporânea distinção entre lei e Direito (com D maiúsculo) a ser pronunciada no caso concreto e sem espaço para a ideia de cisão (nos seus objetivos últimos) entre direito, justiça e bem da pessoa. Tal objetivo é factível somente se existe um renovado empenho para assegurar o cumprimento de duas condições no decidir.

A primeira condição no determinar a quaestio facti, é a disponibilidade para investigar a fundo e com todo cuidado todos os elementos do caso, sem precipitações ditadas pela ideia ilusória de que as previsões abstratas da lei a serem aplicadas ao caso possam ser entendidas como soluções quase geométricas. Nesse sentido, são contraproducentes as iniciativas improvisadas e precipitadas de formação que, embora revestidas do objetivo genérico de ajudar a pessoas, possam provocar a ideia de um direito reduzido a pouco mais que um receituário prático a ser aplicado nas várias situações. Nada mais distante da exigência de descobrir a pessoa que está por trás daquilo que escreveu, como bem indicou o Papa Francisco no seu primeiro discurso 
à Rota. Disso decorre a segunda condição, maiormente inerente à quaestio iuris, isto é, a familiaridade de quem realiza este serviço com os princípios de uma sã hermenêutica canônica, mais complexos do quanto sejam os recorrentes silogismos utilizados na práxis e bem distantes do fácil recurso (não raramente superficial e pouco pertinente) a supostas presunções ou precedentes da jurisprudência. Trata-se de recurso que consiste em mencionar ad colorandum fragmentos de sentenças, rotais ou não. Tal estratégia não resiste a uma séria análise técnica onde se distingue entre o verdadeiro precedente e afirmações feitas superficialmente (quase obter dictum). $\mathrm{O}$ esforço para colher a singularidade de cada causa deveria aumentar mais o recurso ao distinguihsing e não exclui de decidir over rulling, desde que haja uma justificativa.

O necessário recurso à equidade encurta as distâncias entre a lei, enquanto previsão geral que tutela a coerência do ordenamento e a igualdade, e a justiça do caso concreto, que tutela com realismo a centralidade da pessoa, reafirmando, assim, a união inseparável entre justiça e misericórdia. $\mathrm{Na}$ bula de anúncio do recente jubileu, o Papa Francisco afirmou que misericórdia e justiça não são duas realidades diferentes (n.20), mas em outras passagens do mesmo texto (n.21), como em outros do magistério dos seus predecessores, existem expressões que manifestam a dificuldade em se afastar de certa teologia que tende a separá-las, como se para agir com misericórdia fosse necessário desprezar a justiça. Poderia se dizer que desejando pronunciar justiça no caso concreto, é necessário assumir um comportamento performativo mencionado na carta conclusiva do jubileu, uma postura que, ao procurar a verdade e a justiça, coloca no centro a pessoa, não na sua subjetiva individualidade, mas na sua projeção relacional e comunicativa. Isso impede que se entenda a lei como "pedra a atirar" contra as pessoas, mas, ao mesmo tempo, evita um ilegítimo "bonismo destrutivo", que é obra de uma "misericórdia enganadora".

\section{A certeza moral para decidir e a contribuição das partes}

A relação entre legalidade e equidade, entendida como necessidade de se assumir a responsabilidade pela irrepetibilidade do caso, não incide somente na decisão, mas também em seu pressuposto, isto é, a aquisição da certeza moral por meio de uma atividade probatória eficaz, assumindo tam- 
bém em relação a esta última os pontos de vista específicos do caso concreto. A renovada consciência sobre a relação que deve existir entre a verificação judicial da verdade e o convencimento de consciência dos fiéis, exige um cuidado especial na investigação processual, para assegurar que a aproximação aos fatos da causa, diferentemente do quanto possa ter ocorrido na fase pré-processual ou em outros gêneros de discernimento, seja realmente jurídico, isto é, capaz de ajudar cada pessoa a colocar a sua verdade subjetiva em uma relação de verificação construtiva e autocrítica no confronto com outros elementos de verdade, de modo especial com as verdades subjetivas do outro cônjuge.

A este ponto é necessário cair na conta que a reforma predispõe estratégias pré-processuais úteis para assegurar a correta compreensão do sentido do processo, a participação de ambos os cônjuges e a apresentação conjunta, ou ao menos compartilhada, do libelo, prevendo, inclusive, um procedimento extraordinário caso, além da concordância das partes, forem indicadas circunstâncias notórias que, se idoneamente ratificadas pelas partes em seu pedido, possam tornar a nulidade evidente. Esse renovado apreço pela concordância entre as partes, que para outro gênero de causas já está estabelecido pelo can. 1526 como critério para limitar os fatos objeto da prova, não modifica o âmbito da investigação nas causas de nulidade do matrimônio, como se agora o objetivo fosse o de apenas resolver os desacordos ou os conflitos interpessoais entre os cônjuges, ou como se as exigências de verificação não afetassem mais as questões a respeito das quais coincidem. Um juízo à altura da vida e missão da Igreja deve incluir a correspondência da decisão com a verdade. E por verdade nos processos não se pode entender nada que seja diferente da real existência dos fatos enunciados nas declarações, pois somente desta forma a decisão será coerente com o papel que reveste a exigência de verdade na comunidade eclesial.

Reafirmando como única a via judicial para as causas de nulidade, o legislador confirmou a consciência da Igreja de não ter sobre essas causas outro poder senão aquele de natureza meramente declarativa. Como em outros sistemas, o poder judicial eclesiástico tem uma função de garantia dos direitos reconhecidos nas normas substanciais, cuja estrutura é, porém, condicional. Com efeito, as normas substanciais fazem depender da existência de determinados fatos os efeitos nela previstos. Por isso a ação judicial não visa resolver controvérsias, mas, sim, verificar situações qualificadas juridi- 
camente através da investigação de fatos relevantes, colocados como fundamento de tais situações. Isso faz com que a correção jurídica da decisão dependa do quanto esteja conforme ao direito, na quaestio iuris, e conforme a verdade, na quaestio facti, porque se é titular de um direito não porque se possui um reconhecimento formal ou pacífico, mas apenas se são verdadeiros os fatos dos quais depende a existência de tal direito. Não por acaso o legislador adverte que o objetivo da reforma não é multiplicar as declarações de nulidade sem fundamento, mas, sim, a maior rapidez na resolução e na imprescindível análise dos casos. A coincidência razoável entre as partes sobre o andamento dos fatos (não só sobre o objetivo de obter a declaração de nulidade, nem somente sobre motivos aduzidos de direito e tanto menos sobre o procedimento a seguir) é um critério muito concreto sobre a extensão e complemento da investigação que será realizada nos casos singulares, permanecendo firme os mais que conhecidos e igualmente razoáveis alertas para se evitar que as partes terminem por serem juízes em causa própria.

$O$ renovado esforço para não se deparar com barreiras entre o foro da consciência, na qual se dá o discernimento dos fiéis e o discernimento judicial, permanecendo toda cautela para não confundir o juízo subjetivo com a verificação objetiva, levou o código a uma reformulação das normas precedentes sobre o valor das declarações das partes, com a inclusão da sua possível eficácia para a prova plena se idoneamente avaliada por indícios, circunstâncias e elementos de credibilidade. A reforma confirmou e formulou em termos positivos e mais claros esta direção, que incide sobre o conceito da certeza moral necessária, e ao mesmo tempo, suficiente. A certeza moral é habitualmente entendida como estado de ânimo subjetivo da autoridade judicial, embora fundado em dados objetivos, como se constata na doutrina do magistério. É bastante recorrente nos discursos de Pio XII à Rota nos anos 1941 e 1942 e nos discursos de João Paulo II em 1980. O diferente contexto no qual transitava cada Pontífice explica a acentuação de cada um: em um contexto de excessivo formalismo judicial, Pio XII afirma o possível valor suficiente dos indícios, exortando a não exigir além do necessário; em contexto de excessivo subjetivismo e relativismo sobre a solenidade processual, João Paulo II chama a atenção para a exigência de verdade objetiva, respeitando-se um saudável formalismo e evitando-se supervalorizar indícios isolados. 
$\mathrm{Na}$ recente reforma, o art. 12 das Regras de Procedimento retoma o art. 247 da Dignitas Connubii, onde a referida objetividade é contraposta à mera prevalência das provas, conceito já utilizado nas Normae speciali dadas para a Conferência Episcopal dos Estados Unidos antes mesmo do código. Ao comentar a Dignitas Connubii, nunca me deixei contagiar pelo entusiasmo de outros colegas por tal escolha que a consideram uma específica correção do texto normativo, tido como arriscado. Na realidade, a preponderance of evidence, na cultura processual dos Estados Unidos, não é totalmente entendida como automatismo quantitativo que chega a prescindir de um fundamento idêntico àquele da certeza moral. Que a preponderância das provas, menos ainda se interpretada em termos quantitativos, não seja critério automático de objetividade, não significa que o juiz possa chegar a um juízo objetivo por meio de critérios diferentes das mesmas provas, tais como o privilégio, a graça de estado ou um pretensioso intuito pseudo-pastoral. Para o conhecimento dos fatos servem métodos confiáveis, que reduzam a margem de erro, colocando em prática, como instrumentos razoáveis, garantias coerentes com o caráter comunicativo da razão, isto é, as garantias típicas de uma verdadeira discussão judicial, corresponsável na sua dinâmica, aberta, portanto, quanto às formas ou modos, mas detalhada e completa em relação aos fins.

\section{A idoneidade da motivação e a aceitação da decisão por parte dos destinatários}

Entramos, assim, no tema da motivação da decisão, enquanto a objetividade que deve ser o fundamento da certeza moral exige aplicar regras de avaliação por sua vez objetivas e, como tais, aceitáveis e controláveis por todos os participantes do processo. Nas fontes canônicas clássicas, a superação da dúvida razoável sobre fatos a serem investigados não pode ser reduzida somente à uma dimensão subjetiva ou ética que deve inspirar a consciência do juiz ao decidir, mas inclui um preciso vínculo com o acertamento objetivo dos fatos. Por isso sempre sugeri uma conexão entre a dimensão objetiva da certeza moral e a decisão que deve ser apta para convencer em consciência os destinatários dela. O contexto hermenêutico atual, creio, confirma tal pensamento, que comporta algumas exigências referentes às motivações da sentença e, especialmente, a explicação a respeito da análise das 
provas efetuada tendo por base os vários elementos de fato que foram propostos.

Sobre este ponto considero sempre decisivo o esforço para não confundir o princípio do livre convencimento do juiz e da livre avaliação das provas, que são um progresso para absorver a atividade judicial com mais garantias de verdade e equidade, com o princípio do assim chamado íntimo convencimento, que constitui um arriscado desvio rumo a uma avaliação arbitraria, que comprometeria a exigência de legalidade ao julgar, existente também nas causas tratadas nos chamados processos breves. A diferença entre liberdade e arbitrariedade é princípio compartilhado, mas não bem ancorado em regras idôneas que lhe permitam ir além de uma afirmação estéril. A obrigatoriedade de motivar a decisão é o antídoto mais eficaz para evitar a arbitrariedade; mas a respeito do modo de fazê-lo os temas são abertos. O principal talvez seja aquele de dar um significado mais aceitável àquela falta de motivação que afeta a sentença de nulidade sanável; outros temas se referem ao momento e ao modo de estabelecer as motivações a serem indicadas e ao estilo empregado para realiza-la. Na atual reforma estes temas não foram enfrentados com novas normas, mas em certos aspectos valorizados de modo renovado no seu contexto hermenêutico, especialmente na dinâmica da sinodalidade da qual derivam algumas sugestões.

Se o princípio de legalidade próprio do exercício do poder judicial deve atingir, como foi dito, a dimensão factual, é necessário que se chegue à determinação dos fatos históricos tendo por base regras que exprimam a própria convicção em proposições representativas da realidade e colocadas como base técnica de motivações in facto que sejam comuns e controláveis. Com isso quero dizer que se trata de regras que recaem sobre todos, não somente sobre os juízes; e mais, tais proposições, tendo por base regras objetivas, deveriam ser formuladas pelos técnicos do direito que são encarregados de fazer valer as razões da defesa do vínculo e da defesa das partes na discussão prévia à decisão. Esses dois deveres da defesa técnica são o rosto concreto da sinodalidade na fase processual e são o modo previsto no nosso ordenamento (e em todos os ordenamentos justos) para colaborar de modo corresponsável com a administração da justiça confiada ao poder judiciário. Esta, por definição, não seria concebível em modalidades autárquicas e voluntaristas, sem o devido apoio em um contraditório tecnicamente eficaz. Impressiona examinar sentenças em cujas motivações não há qualquer refe- 
rência às alegações defensivas dos patronos e nem da defesa do vínculo. É certo que, não raramente, os restrictus e as animadversiones são impostadas de maneira retórica, narrativa e bem pouco ancorada nas referidas regras de avaliação das provas.

Sobre este ponto, a questão mais delicada se refere a avaliação das provas livres, entendidas como aquelas em que a lei se limita a estabelecer os critérios que o juiz deve seguir quando assume este encargo. Embora dados para a avaliação da prova testemunhal, os critérios fixados pelo cân. 1572 (condições, fonte e tempo de conhecimento, coerência e concordância) são válidos para avaliar cada meio de prova livre. Portanto, o cân. 1572 estabelece o standard concreto de avaliação para distinguir, nas causas canônicas (ordinária ou breviora) entre convencimento livre e convencimento arbitrário ou íntimo, não permitindo ao juiz de interpretar o primeiro como se estivesse isento de qualquer critério racional ou de qualquer vínculo na avaliação dos fatos emergidos. As regras do cân. 1572 são racionais e também vinculantes ex lege, pois indicam o caminho que o juiz deve percorrer para formar a sua convicção. Embora racionais, são regras técnicas que, na decisão das causas tratadas segundo o processo brevior, precisam, também, ser observadas. Compete aos dois técnicos do direito (instrutor e assessor) apresentá-las ao Bispo na consulta obrigatória que este é obrigado a ter com eles. As novas normas não impõem a realização de tais consultas segundo as modalidades previstas para a decisão colegial dos processos ordinário. Todavia, considerando os objetivos estritamente técnicos de tal consulta, especialmente em vistas do devido fundamento da decisão exclusiva do Bispo, a partir de uma avaliação objetiva e técnica das provas, não me parece insensato invocar a norma prevista para as decisões colegiais como regra dada para os casos similares, isto é, a convocação para um confronto conjunto, permanecendo intacta obviamente a sua natureza não deliberativa.

A qualidade da motivação in facto reside na cuidadosa conjunção entre avaliação global da causa e avaliação dos meios de prova, aplicando sobre fatos singulares, principais e secundários, os critérios objetivos de avaliação indicados pela lei. A avaliação global apoia-se numa avaliação analítica, daí a necessidade de na motivação da sentença se fazer um esforço para explicar em detalhes por quais motivos previstos por lei um determinado fato foi considerado moralmente certo ou não. Não se deve omitir os fatos que poderiam provocar uma decisão na direção oposta e se deve evitar que se 
confunda a certeza moral com a prevalência de provas em relação aos fatos que forem objeto de versões contrastantes. A meu ver, no atual contexto, é obrigatório evitar que as motivações consistam em uma série de enunciados apodíticos de fatos colocados como fundamento da decisão, ao invés de se pautarem por uma explicação das razões pelas quais tais fatos são tidos como certos.

Um aceno específico merece também a eventual visão compartilhada das partes, especialmente se alguns fatos da causa, ligados talvez de maneira indireta ao motivo de nulidade aduzido, foram invocados pela parte demandada ao solicitar à parte demandante o reconhecimento da existência deles. Será frequente que a parte demandada, para aderir à causa e participar com convicção das investigações, pretenda este reconhecimento, mesmo quando se tratar de fatos que, devido ao enquadramento jurídico do caso, vão além do dispositivo legal. Tanto nos processos ordinários quanto nos assim chamados processos mais breves, considero pouco adequado ao renovado contexto hermenêutico deixar de lado tais aspectos na redação das motivações da sentença, nem mesmo por razões de brevidade. Frequentemente tais aspectos, aparentemente secundários, exprimem elementos não desprezíveis das relações interpessoais e familiar que, de fato, foram vividos entre as partes, razão pela qual não seria correto ignorá-los por completo nas explicações da decisão.

\section{As obrigações decorrentes da sentença: a responsabilidade familiar e o desejo de família}

Entramos assim na questão das obrigações decorrentes da sentença, que conduz às exortações sobre obrigações naturais que devem se cumprir em relação ao cônjuge e à prole, bem como ao possível veto de contrair novas núpcias sem consultar o ordinário. Nos textos da reforma do processo de nulidade matrimonial há um reenvio às normas do código, sem outras especificações.

A primeira questão é muito desconsiderada na prática dos tribunais de todos os graus e tipos. Pouco serve alongar-se para demonstrar que o renovado contexto hermenêutico, constituído pelos objetivos de partir novamente da família na evangelização, exige uma inversão de tendência que liberte os enunciados sobre o ato constitutivo do qual surge o matrimonio válido do 
risco de se mover em uma intolerável abstração, que prescinde do estado de vida de fato iniciado com o matrimonio putativo, e do qual resultam responsabilidades e expectativas entre os cônjuges e a prole que, ao menos em termos exortativos estabelecidos pela lei, são dignas de tutela. Produz certo desconcerto a exiguidade das perguntas e das investigações processuais a respeito do desenvolvimento da convivência conjugal, como se fosse irrelevante para verificar a existência ou não de lacunas na formação do consentimento. A inversão de tendência, além de uma maior completeza instrutória, exige que os operadores do direito sejam formados no direito de família e no direito dos menores, seja na perspectiva canônica, seja na civil. Devese promover do melhor modo possível as permanentes e comuns responsabilidades dos cônjuges em relação aos deveres de educação integral (também religiosa) da prole, bem como ao empenho de cada um (embora diversificado) em seu adequado sustento. Merece atenção específica do colégio em sede de decisão, e não só do ponente na fase da redação, a questão do modo de mencionar na sentença aqueles aspectos que na legislação civil se prestam a ulteriores instrumentalizações que desagregam as responsabilidades comuns dos pais, como ocorre com a incapacidade psíquica.

Quanto ao veto de passar a novas núpcias, já a instrução Dignitas Connubii oferecia critérios, cuja generalizada desatenção é ainda menos justificada no contexto da reforma. Exceto nos dois casos em que o motivo de nulidade presente comporta, de fato, a nulidade de qualquer outro matrimônio futuro (como no caso da impotência absoluta ou da incapacidade permanente), a imposição de veto se deixa à prudência dos juízes, evitando, portanto, qualquer automatismo, muitas vezes presente nas práticas dos tribunais. Espero que isso ocorra por escrúpulo, em todo caso injustificado, ou por preguiça intelectual no estudo dos casos, enquanto espero que não haja outros interesses, menos aceitáveis, e que se referem ao procedimento da remoção do respectivo veto. Ao renovado valor de celeridade se acresce a devida cautela sobre este ponto.

\section{A dedicação prioritária: tempo e destinação da decisão}

Tal celeridade na atividade judicial, compatível com o discernimento de consciência prévio ao processo e com o sucessivo discernimento pastoral, destinado a favorecer uma mais plena integração dos destinatários da sen- 
tença na vida da comunidade eclesial, reafirma a exigência de dedicação prioritária a este serviço. Tal exigência, novamente invocada pelos sínodos, deve ser atendida, não só para evitar os riscos de agir na decisão com orientações próprias de um receituário ou segundo um automatismo nada respeitoso com a singularidade dos casos (como aqueles acima indicados a respeito do veto a novas núpcias). A exigência de dedicação prioritária deve ser atendida para assegurar que a publicação e entrega da sentença dentro de um mês da data da decisão não seja ainda uma exceção (como de fato ocorre), mas sim a regra (a norma de lei).

Além da questão do mencionado prazo, se acrescenta a necessidade de que o texto da sentença seja redigido de modo a favorecer o discernimento pastoral sucessivo, a cargo de outros operadores. Sem dedicação prioritária ao serviço judicial é uma quimera atribuir à sentença esta função ulterior. Entendo, porém, que o discernimento judicial dos fatos de projeção interpessoal e familiar verificado no processo, seja uma contribuição de primeira ordem para ajudar as pessoas a prosseguir na revisão de vida, na conversão e em uma maior e responsável integração na vida da Igreja.

No que se refere ao caso específico das sentenças negativas, permanecendo (como para as sentenças afirmativas) o direito de apelação, o acertamento dos fatos verificados no processo poderia ajudar a avaliar se existe, contudo, elementos para ulteriores iniciativas judiciais e sua possível projeção a respeito da validade da união ou, onde o caso o sugerir, para pronunciar a legitima separação manente vinculo também coram Ecclesia.

\section{Conclusão}

A reflexão proposta poderia suscitar certo ceticismo. É possível que os aspectos que foram sugeridos como caracterizantes do atual contexto hermenêutico não sejam totalmente compartilhados, ou, então, que mesmo compartilhando da sua relevância no contexto da reforma, não pareça tão clara a incidência de cada um na interpretação e aplicação da imutável disciplina sobre a sentença no novo processo matrimonial. Frequentemente a desconfiança sobre temas da administração da justiça na Igreja não se refere à disfunção do seu sistema, mas à sua organização, considerando sempre que não há pessoas e estruturas a altura para sustentar com competência a atividade judicial, especialmente naquilo que se refere à sua componente 
mais específica, que é a discussão tendo por base argumentos e instrumentos técnicos.

Em tal caso, porém, deveria ser óbvio que a solução não possa consistir em redefinir pouco a pouco a aplicação do método judicial na sua qualidade, confiando em outros métodos gravemente expostos a erro. Em tal caso, a consciência derivada de uma correta discussão racional e intersubjetiva (como aquela típica do serviço judicial) é substituída por uma consciência sem garantias racionais, fundada em um presumível (ou mesmo presunçoso) sentido pastoral, feito de instituições, onde a verificação da realidade pode ocorrer só por um milagre que o Senhor até pode, mas não está obrigado a conceder.

\section{Bibliografia}

A. Ripa, La novità mancata. Il valore probativo delle dichiarazioni delle parti dal CIC 1983 alla Dignitas Connubi; il contriburo della giurisprudenza rotali. Città del Vaticano 2010.

E. Di Bernardo, Il sillogismo giudiziale. Prerrogative e limiti di applicabilità nel processo canonico, in Apollinaris 77 (2004), 415-453.

Francisco, Discurso a la Rota Romana, 24.1.2014, en AAS 106 (2014), 8990;

G. Caberletti, La motivazione della sentenza canonica, en P. Gherri (a cura di), Decidere e Giudicare nella Chiesa. Atti della Vi Giornata canonistica interdisciplinare, Città del Vaticano 2012, 259 ss.

G. Ubertis, Razionalismo processuale e verità, en Id., Il giusto processo civile, Milano 2013, 327-332.

J. Ferrer Beltràn, La valoraciòn racional de la prueba, Madrid-Barcelona 2007.

J. Ferrer Beltràn, Prueba y verdad en el proceso, Madrid 2005;

L. Baldisseri (a cura di), A cinquant'anni dall'Apostolica sollicitudo. Il Sinodo dei Vescovi al servizio di una Chiesa sinodale, Città del Vaticano 2016. 
M. Gronchi, Amoris Laetitia. Una lettura dell'esortazione apostolica postsinodale sull'amore nella famiglia, Cinisello Balsamo 2016.

M. J. Arroba Conde - C. Izzi, Pastorale giudiziaria e prassi processuale nelle cause di nullità del matrimonio, Cinisello Balsamo 2017.

M. J. Arroba Conde - M. Riondino, Introduzione al diritto canonico, Milano 2015, 183-185.

M. J. Arroba Conde, Convincimento, certezza e motivazione: l'esperienza canonica, en Criminalia (2012), 163-180.

M. J. Arroba Conde, Corresponsabilità e diritto processuale, in Apollinaris 82 (2009), 201-225.

M. J. Arroba Conde, Cuestiones fundamentales de derecho probatorio canónico, en R. Rodríguez Chacón (ed.), Puntos de especial dificultad en derecho matrimonial canónico, sustantivo y procesal, y cuestiones actuales de derecho eclesiástico y relaciones Iglesia - Estado (XXVII Jornada de la asociación de canonistas españoles (11 al 13 abril), Madrid 2007, 105-129.

M. J. Arroba Conde, Diritto processuale canonico, $6^{\circ}$ ed., Roma 2012.

M. J. Arroba Conde, Giusto processo e peculiarità culturali del processo canonico, Roma 2016, 178.

M. J. Arroba Conde, La pastoral judicial y la preparación de la causa en el m.p. Mitis Iudex Dominus Iesus, in M. E. Olmos Ortega (ed.), Procesos de nulidad matrimonial tras la reforma del papa Francisco, Madrid, 2016, 63-82.

M. J. Arroba Conde, La reciente experiencia sinodal y la reforma procesal, en Anuario de derecho canónico 5 (2016), 165-192.

M. J. Arroba Conde, Le dichiarazioni delle parti come valorizzazione della dimensione personalista del processo matrimoniale canonico, in Apollinaris 80 (2007), 687-712;

M. J. Arroba Conde, Prova e difesa nel processo di nullità del matrimonio canonico. Temi controversi, Lugano 2008, 45-56; 
M. J. Arroba Conde, Relaciòn entre las pruebas y la comprobaciòn de la verdad en el proceso canònico, en Anuario de derecho canonico 1 (2012), 11-36.

M. J. Arroba Conde, Risultati della prova e tecnica motivazionale nelle cause di nullità matrimoniale. Casi pratici di prima istanza, Città del Vaticano 2013,5 ss.

M. J. Arroba Conde, sub can. 1682, en A. Benlloch Poveda (ed.), Código de derecho canónico. Edición bilingüe, fuentes y comentarios de todos los cánones, 16 ed., Valencia 2016, 735.

M. J. Arroba Conde, La misericordia nel diritto occidentale, en Monitor Ecclesiasticus 130 (2015), 540; F. J. Urrutia, Aequitas canonica in Periodica 73 (1984) 57 ss.

M. Riondino, Famiglia e minori. Temi giuridici e canonici, Città del Vaticano 2011.

M. Riondino, L'evoluzione del concetto di interesse del minore nella cultura giuridica europea, in Civitas et Iustitia 6 (2008), 389-411.

M. Riondino, La mediazione come decisione condivisa, in Apollinaris 84 (2011), 607-631.

M. Taruffo, Comentarios, in J. Ferrer Beltràn - C. Vàzquez, Debatiendo con Taruffo (eds.), Madrid 2016, 419.

M. Taruffo, Idee per una teoria della decisione giusta, in Id., Sui confini. Scritti sulla giustizia civile, Bologna 2002, 225-228; Id., La semplice verità, 117-118;

M. Taruffo, La motivazione della sentenza civile, Padova 1975;

M. Taruffo, La prova dei fatti giuridici. Nozioni generali, Milano 1992;

M. Taruffo, La semplice verità. Il giudice e la costruzione dei fatti, Bari 2009;

P. A. Bonnet, Giudizio ecclesiale e pluralismo dell'uomo, Torino 1998, 26.

P. Bianchi, Alcune annotazioni circa l'interrogatorio di parti e testi nelle cause di nullità di matrimonio, in Quaderni di diritto ecclesiale 17 (2004), 210-223. 
P. Bianchi, Aspectos pastorales de la reciente reforma procesal, en Commentarium pro religiosis 97 (2016), 25 ss.

$\mathrm{P}$. Bianchi, El proceso màs breve ante el obispo, en L. Ruano - C. Guzmán (eds.), Reformas de los procesos de nulidad y otras novedades legislativas, Dykinson, Madrid 2017, 249-278. 